\title{
Regina y Juan Salva: primeras grabaciones de cantos mapuches en soporte cilindros de fonógrafo (1905 y 1907)1
}

\section{Regina and Juan Salva: First Recordings of the Mapuche Songs on Phonograph Cylinders (1905 and 1907)}

\author{
por \\ Margarita Canio Llanquinao ${ }^{2}$ \\ Departamento de Lenguas y Traducción \\ Facultad de Artes y Humanidades \\ Universidad Católica de Temuco \\ mcanio@uct.cl \\ Gabriel Pozo Menares ${ }^{3}$ \\ Departamento de Antropología \\ Facultad de Ciencias Sociales \\ Universidad Católica de Temuco \\ gpozo@uct.cl
}

Regina y Juan Salva fueron dos personas trasladadas a la ciudad de La Plata durante la denominada "Campaña del Desierto" (1878-1885). En ese contexto se registraron algunos cantos y diálogos en los antiguos cilindros de cera, responsabilidad del investigador Robert Lehmann-Nitsche. Hemos tomado dos de esas grabaciones, transcribimos sus contenidos en mapudungun y los tradujimos al castellano, con el objetivo de difundir uno de los archivos históricos más importantes para la memoria oral mapuche y de la humanidad.

Palabras clave: archivos sonoros, cilindros de cera, cantos mapuches, memoria histórica.

1 El presente documento es resultado de una pasantía de investigación realizada en diversas instituciones alemanas, entre los años 2010 y 2011. Queremos agradecer a las siguientes personas del Museo Etnológico de Berlín: Dra. Susanne Ziegler y Albrecht Wiedmann, Departamento de Etnomusicología; Dra. Manuela Fischer, Colección Arqueología Sudamericana. También al director del Departamento Legados y Colecciones Especiales, Instituto Ibero-Americano de Berlín, Dr. Gregor Wolff.

2 Licenciada en Educación y Master en Estudios Americanos. Investigadora especialista en lengua y cultura mapuche, responsable del proyecto FONDART 35568, año 2012.

3 Doctor en Historia y Antropología de América. Sus investigaciones se centran en la memoria oral y su implementación en ámbitos educativos. Responsable del Proyecto FONDECYT 11130679, año 2013-2016. 
Two Mapuche persons - Regina and Juan Salva - were captured during the so called "Campaña del Desierto" (the Desert Campaign) (1878-1885) in Argentina. They were taken to La Plata city where the scholar Robert Lehmann-Nitsche recorded on wax cylinder some of their songs and dialogs. Two of these recordings are considered in this document. The texts in Mapudungun (the Mapuche language) were transcribed and then translated into Spanish. The purpose is to make widely known one of the most important sound archives of the history of the Mapuche people and mankind.

Key words: sound archives, wax cylinders, Mapuche songs, oral memory.

\section{INTRODUCCIÓN}

En junio de 2010 iniciamos una investigación que consiste en revisar gran parte de los archivos manuscritos, fotográficos y fonológicos sobre la sociedad mapuche, conservados actualmente en Alemania (Berlín y Múnich). Algunos antecedentes nos llevaron al Instituto Ibero-Americano de Berlín ${ }^{4}$, en el que se han catalogado documentos inéditos del investigador Robert Lehmann-Nitsche (1872-1938), quien se desempeñó como director del Departamento de Antropología en el Museo de La Plata, Argentina, entre los años 1897 y $1930^{5}$. Los manuscritos con contenidos en lengua mapuche se agrupan en tres legajos de casi mil páginas cada uno, de ellos $80 \%$ se encuentra sin traducción al castellano ${ }^{6}$. Este trabajo está siendo editado con un enfoque lingüístico por Marisa Malvestitti ${ }^{7}$. Por nuestra parte elaboramos una traducción con enfoque histórico en el marco del Proyecto Fondart $\mathrm{N}^{\circ}$ 35568, año 2012, titulado "Traducción de manuscritos en lengua mapuche, obra inconclusa del investigador Robert Lehmann-Nitsche (1872-1938)", cuyo resultado fue la publicación de un libro que incluyó gran parte del legado como obra póstuma ${ }^{8}$.

El segundo legajo de manuscritos, denominado Textos Araucanos II, se inicia con seis páginas tituladas "Fonogramas Araucanos", separadas en 1a, 1b, 2, 3, 4-5, 6 y 7. Como nota al pie en la página $1 \mathrm{~b}$ el investigador escribió "Los fonogramas están depositados en el Archivo del Instituto Psicológico de la Universidad de Berlín"9.

Con estos datos comenzamos la búsqueda de aquellos fonogramas con poco éxito, ya que la Universidad a la que se hacía referencia no tiene una sección encargada de ese tipo de materiales. Sin embargo, en un libro que compila los fonogramas conservados en el Museo Etnológico de Berlín ${ }^{10}$, aparece una descripción de los cilindros de cera que grabó Lehmann-Nitsche, entre ellos, siete dedicados al grupo "Araukaner" (mapuche, denominados araucanos por la bibliografía hasta avanzado el siglo veinte). Fue así como recurrimos al Departamento de Etnomusicología del Museo mencionado ${ }^{11}$, lugar donde se acopian dichos cilindros. Si bien no estaban digitalizados, tanto la Dra. Susanne Ziegler como Albrecht Wiedmann (encargados de la sección) hicieron las gestiones para obtener un $\mathrm{CD}$ con 8 pistas en formato de audio.

En el presente documento describimos dos de aquellas grabaciones de acuerdo con los siguientes pasos: escucha, transcripción, traducción, corrección, propuesta final. Según los

4 Ver su página web http://www.iai.spk-berlin.de/es/home.html (consultada el 17/03/2013).

5 Por mayores detalles sobre la biografía y obra de Robert Lehmann-Nitsche véase Bilbao 2004 y Farro 2009.

6 Canio 2011: 73.

7 Véase Malvestitti 2012, 2008 y 2007.

8 Véase Canio y Pozo 2013 y la reseña escrita por André Menard que figura en el presente número de la $R M C h$.

9 Legajo Textos Araucanos II, Instituto Ibero-Americano de Berlín, código de página Y-4.

10 Ziegler 2006.

11 Ver su página web http://www.smb.museum (consultada el 17/03/2013). 
títulos que les asignó el investigador Lehmann-Nitsche, ambos están rotulados como cantos "machitun"12. No obstante, estos corresponden a una mirada externa de categorización que no necesariamente corresponde al tipo de canto. Lo más posible es que las entonaciones de Regina y Juan Salva hayan sido tayül o pillañtun, los que tienen connotaciones sagradas y se ejecutan en algunas actividades rituales, para ello un/una machi establece contacto con los "seres espirituales". Esto solo se puede interpretar a la luz de las variedades de canto que actualmente siguen vigentes en el conocimiento oral mapuche, pero sería riesgoso extrapolarlos a las fechas en que fueron registradas las grabaciones.

El objetivo que proponemos es presentar, describir y difundir uno de los más antiguos archivos sonoros que se conservan sobre el "canto mapuche". Gracias al trabajo de restauración realizado por personal del Museo Etnológico de Berlín se logró tener acceso a ellos hoy, de modo de recuperar un antecedente fundamental para la memoria oral de los pueblos originarios y de la humanidad.

\section{ANTECEDENTES BIBLIOGRÁFICOS}

Las conversaciones, cantos y música popular ha sido objeto de recopilación desde principios del siglo veinte gracias a la invención del fonógrafo, primer aparato tecnológico que permitió el registro de audio. En Chile, uno de los precursores de este tipo de grabaciones fue Efraín Band. Con la contingencia del Bicentenario, el diario La Tercera le dedicó estas palabras: "Las grabaciones sonoras más antiguas de Chile hechas por el primer disquero de Santiago, Efraín Band, sobre un par de cilindros de Edison [...], se fueron a España cuando en el 2008 murió su propietario, el coleccionista de música chilena Juan Astica. Band había grabado cuecas, pianistas y cantantes en fondas y casas de canto de Santiago entre 1906 y 1914 [...]. La primera grabación conocida es de 1906, del Trío Fru-Fru, de Ismael Carter y sus hermanas. Cantan La Santiagueña, El Arbolito, Noche Buena en la Alameda, y otras"13.

Así como la música tradicional criolla formó parte de los tempranos registros sonoros, algunos investigadores se dedicaron especialmente a los pueblos originarios. Tomando como referencia el sur de Chile y Argentina, las primeras grabaciones se efectuaron en Tierra del Fuego. "Los artífices de estas grabaciones fueron el explorador y militar norteamericano Charles Wellington Furlong, quien tomó entre los años 1907 y 1908 cantos y locuciones verbales de aborígenes selknam (ona) y yagan con un fonógrafo Edison y 13 cilindros de cera; el misionero y antropólogo alemán Martin Gusinde, quien grabó en 1923 un vocabulario y diversos cantos de aborígenes alakaluf, selknam y yagan con 30 cilindros de cera; y su colega y correligionario Wilhem Koppers quien presumiblemente registró en 1922 cantos y expresiones verbales de aborígenes alakaluf y yagan con 33 cilindros"14. Fue en estas mismas fechas que otro investigador alemán, Robert Lehmann-Nitsche, hacía sus

12 Machitun es una palabra genérica que se usa para referirse a la ceremonia de sanación que realiza el/la machi (persona dedicada a la salud física y espiritual).

13 Véase diario La Tercera, sábado 18 de septiembre de 2010, página 36, "La banda sonora del Centenario”, por Roberto Farías. Disponible en http://diario.latercera.com/2010/09/18/01/ contenido/santiago/32-38993-9-la-banda-sonora-del-centenario.shtml. Ver además Garrido y Menare 2014.

14 García 2011:38. Se recomienda este artículo, ya que el autor genera una discusión sobre la ideología y tecnología bajo la que se recopilaron estos fonogramas y el posterior análisis que hicieron los científicos bajo la perspectiva musicológica comparativa de carácter colonialista. Para el caso de la música alacalufe ver Grebe Vicuña 1974 por un estudio etnomusicológico sobre el proceso de 
grabaciones en la ciudad de La Plata y sus alrededores, cuya producción es una de las más abultadas: 246 cilindros, que incluyen música popular y aborigen ${ }^{15}$.

Centrando la atención en el pueblo originario mapuche, denominados "araucanos" en aquella época, hay referencias que datan de 1911 cuando el misionero capuchino Félix José de Augusta hace las primeras recopilaciones musicales en las cercanías de Panguipulli16, quien gracias al fonógrafo grabó 10 cantos, transcribió su letra e hizo los pentagramas de las melodías ${ }^{17}$. Augusta optó por buscar algunas nomenclaturas en lengua mapuche en donde Julián Weitra, su hermano Domingo Weitra y Domingo Segundo Wenuñamko se referían a las entonaciones, mientras que otras las fichó en lengua alemana. Desde el canto $\mathrm{N}^{\circ} 1$ hasta el $N^{\circ} 6$ los clasificó como yanéùlùn [yüne-ül-ün] y lo tradujo al alemán como "den Gesang beherrschen" o "Meistergesang" (dominador del canto o maestro del canto). El N 7 no lo clasifica, sino que lo describe como "wird mit Begleitung des trompe" (acompañado con el trompe). El $\mathrm{N}^{\circ} 8$ pertenece a la clase llamékan, canciones de las mujeres mientras muelen el trigo con la piedra molino llamada kuzi, entre otras actividades cotidianas. El $\mathrm{N}^{\circ} 9$ lo clasifica como "machi-Lied" o machi ül (canto de machi). El N 10 lo nombra "Festgesang" (canción de fiesta), la que se sitúa específicamente en la inauguración de una casa nueva.

Por la relación que tiene con los cantos de machi "machitun" que grabó LehmannNitsche, a continuación transcribimos y traducimos el que interpreta Domingo Segundo Wenuñamko ${ }^{18}$ :

Moyean pilaimi te? Moyean ya pilaimi te? Fəreneqeimeu yənečen. Akuleleimi mariepu raniñwenu llaweñ mai tami moyeam, tami fəreneeten raniñwenu yənečen. Fəreneqeimeu yənečen, elueimeu mariepullaweñ mai.
¿Acaso no has dicho "viviré"? ¿Acaso no has dicho "viviré"? Te ha favorecido Ngünechen ${ }^{19}$, te trajo doce hierbas medicinales desde el medio del cielo para que puedas sobrevivir, porque te ha favorecido Ngünechen que habita en medio del cielo. Te ha favorecido Ngünechen, quien te entregó doce hierbas medicinales.

Este tipo de material resultó ser sumamente atractivo para investigadores posteriores, por ejemplo Carlos Lavín²0, Pedro Humberto Allende 21 y Carlos Isamitt, quienes hicieron varios acercamientos in situ a las comunidades mapuches para investigar y analizar las características de su música. Isamitt escribe que "Humberto Allende y Carlos Lavín, del grupo de promotores de la evolución musical, se dieron a la búsqueda y al estudio fervoroso de los cantos del pueblo, tratando de comprender en ellos la idiosincrasia

aculturación y cambio estilístico. Para un análisis en el contexto mundial en tanto uso del "gramófono", ver Kittler 1999.

15 Chicote y García 2009:106. La cantidad de cilindros grabados varía según la fuente entre 243 y 246.

16 Panguipulli en la actualidad es una comuna cordillerana ubicada en la Región de Los Ríos, Chile.

17 Véase Augusta 1911: 684-685. Los pentagramas están entre las páginas 687 y 698.

18 Augusta 1911: 697. Se ha respetado íntegramente el alfabeto usado por el autor en estos pentagramas; solo hemos eliminado las barras /-/ que separaban las sílabas. La propuesta de traducción es nuestra.

19 Ngünechen es considerado uno de los seres de mayor relevancia en la espiritualidad mapuche. Como se verá más adelante, también es denominado Chaw Ngünechen o Chaw (en su acepción masculina) y $\tilde{N} u k e \ddot{U} l m e n$ (en su acepción femenina). En las traducciones mantenemos estas nomenclaturas.

20 Lavín 1967.

21 Allende 1945. 
del hombre [...]. Al aventurarse por esta ruta inexplorada, fueron recogiendo bellezas inéditas, motivos de interés en las costumbres, en los trabajos, en las fiestas típicas, en las reacciones vitales" ${ }^{22}$. Además Lavín, en uno de sus viajes a Europa, se dedicó a buscar materiales de archivo sobre los "araucanos", llegando así a las grabaciones en cilindros de cera hechas por Félix de Augusta ${ }^{23}$. Ello sirvió como motivación para producir pequeñas composiciones para piano, para conjunto de cámara y para canto y piano, entre ellas Mitos araucanos y Lamentaciones huilliches, publicadas en 1928 por la Edición de Música Boileau de Barcelona24.

Con una descripción más detallada sobre sus trabajos de campo, Carlos Isamitt da cuenta de su participación en un "machitún" - ceremonia ofrecida por el/la machi para sanar a una persona enferma (en lengua mapuche es zatun)-, anotando los ritmos del kultrun (timbal), entre otros instrumentos. Además identifica que "La «machi» despliega una riqueza de acentos y de ritmos de acuerdo con la significación de las palabras del canto [...]. Sobreviene un largo período en que el canto toma nueva expresión de firmeza, seguridad, ayudado por la elocuencia de la percusión"25. Si bien hace referencia a estos cantos, no es hasta el año siguiente (1935) que publica un machi üly otros fragmentos de "cantos de machitun", para ello también propone una transcripción de sus contenidos y elabora los pentagramas respectivos. A continuación se presenta como ejemplo el canto que obtuvo gracias a una machi de la comunidad Chapod, en un lugar cercano a Maquehue y Temuco 26 :

\begin{abstract}
¡Mari mari witran mapu, mari mari witran mapu, éllañei tami amuan. Mari mari, mari mari witran mapu. Amun antü kənu pəllün kənu pəllün, amun antü kənu pəllün, nonén chau Nonéchén; machi ñei, machi ñeimi wente wenü pille neu nga rañi ñu wenü machi ñeimi meli rayen elneu nga chawəm meu, ñuke ülmen chawəm meu ñuke ülmen chawəm meu!
\end{abstract}

Entre este canto de machi y el que recopiló Augusta dos décadas antes, se visualiza una correspondencia en cuanto a los ritmos y, principalmente, en los contenidos que muestran la vinculación entre el mundo cotidiano (terrestre) y el espiritual (celeste). Pero el elemento más destacable de aquel recopilado por Isamitt es que, por primera vez, se obtiene de la misma voz de una machi; mientras que Augusta recurre a un interlocutor que lo replicó después de haberlo escuchado. Se produce así un acercamiento más preciso que permite comprender los estilos con mayor claridad.

22 Isamitt 1957: 27-28.

23 Salas Viu 1967: 9.

24 Salas Viu 1967: 8. Ver además Urrutia Blondel 1967.

25 Isamitt 1934: 8.

26 Isamitt 1935: 10-11. Se ha respetado íntegramente el alfabeto usado por el autor en estos pentagramas; solo hemos eliminado las barras /-/ que separaban las sílabas, aglutinamos algunas palabras y agregamos signos de puntuación para hacer más comprensible la lectura en lengua mapuche. La propuesta de traducción es nuestra.
¡Hola [hermano del] territorio aliado, hola [hermano del] territorio aliado, es hermoso el lugar donde vas, hola [hermano del] territorio aliado. Al irse el sol, también se va el espíritu, también el espíritu, porque así lo quiere Chaw Ngünechen. "Es machi, serás machi arriba del cielo" eso me ha dicho, "serás machi de en medio del cielo". Chaw me entregó cuatro flores, Nuke Ülmen y Chaw, Nuke Ülmen y Chaw! 


\section{CILINDROS DE CERA GRABADOS POR LEHMANN-NITSCHE Y SU LUGAR DE CONSERVACIÓN}

A comienzos del siglo veinte, Robert Lehmann-Nitsche compiló 243 grabaciones en cilindros de cera junto con varios representantes de los pueblos originarios de América del Sur y cantantes del folclore popular argentino ${ }^{27}$. Para que estos fuesen estudiados con mejores técnicas metodológicas de sonido, los envió a Berlín. Estos cilindros sobrevivieron a sus traslados entre diversas instituciones y también a los bombardeos producidos en el marco de la Segunda Guerra Mundial. La última institución que los recibió, lugar donde se conservan en la actualidad, es el Archivo Fonográfico de Berlín, sección especial del Museo Etnológico para todo lo relativo a archivos sonoros. La tarea principal de este Archivo "ha sido y sigue siendo la colección, la presentación y el estudio de documentos sonoros de las más diversas culturas musicales del mundo [...]. El significado de las colecciones del Archivo Fonográfico de Berlín ha de verse sobre todo en su dimensión histórica: los cilindros Edison son considerados los soportes de sonido más antiguos [...]. Allí donde estos documentos histórico-sonoros fueron grabados, muchas veces, no se sabe casi nada de su existencia. Por ello, resulta de gran interés a nivel mundial hacer estas grabaciones audibles de nuevo y devolverlas a sus lugares de origen" 28 .

En 1998 el Archivo inició un proyecto denominado Salvamiento de la mayor colección de los más antiguos documentos sonoros de música tradicional de todo el mundo - restauración y regrabación de las célebres colecciones de cilindros y discos de goma laca del Archivo Fonográfico de Berlín, 1893-1954, cuyos resultados son la edición y publicación de varios CD con sus respectivas investigaciones. Sin embargo, Susanne Ziegler deja constancia que muchas grabaciones tienen que ser consideradas irrecuperables, ya que los cilindros están enmohecidos, gastados, rotos, estropeados o perdidos ${ }^{29}$. Por otra parte, el ingeniero en sonido Albrecht Wiedmann advierte que "Quizás se sorprenda quien escuche por primera vez las grabaciones de estos $\mathrm{CD}$, por la mala calidad del sonido. Desgraciadamente, en lo que se refiere a las grabaciones de cilindros del Archivo Fonográfico de Berlín, esto es más a menudo la regla que la excepción; las condiciones que han sufrido las colecciones desde su grabación hace más de 100 años, ha tenido sus impactos" 30 . De esta manera, y con todas las dificultades que implica, el hecho de que las grabaciones sean mínimamente audibles, se considera una reliquia desde el punto de vista de su conservación histórica y un legado fundamental para conocer las culturas de los pueblos originarios.

El caso específico de la colección "Araukaner" [Mapuche] (ver Imagen 1) está integrada por siete cilindros de cera originales - color café claro-y tres copias - cera de color negro y en cobre-, guardados en una caja compartida con los del pueblo chorote. Se conserva además una carpeta con manuscritos y datos sobre las "características de la música mapuche" elaborados por el mismo Lehmann-Nitsche.

Uno de estos cilindros, el número 2, fue publicado por Robert Lehmann-Nitsche, en Walzenaufnahmen aus Argentinien 1905-1909 bajo el nombre "canto femenino" de Regina ${ }^{31}$. Los demás fueron digitalizados por Albrecht Wiedmann el año 2010, recuperándose así

27 Ziegler 2009: 73.

28 Koch, Ziegler y Göbel 2009: 69.

29 Ziegler 2009: 72.

30 Wiedmann 2009: 72.

31 García 2009. Es un extracto de la primera parte del canto, con una duración de 1' 21". 

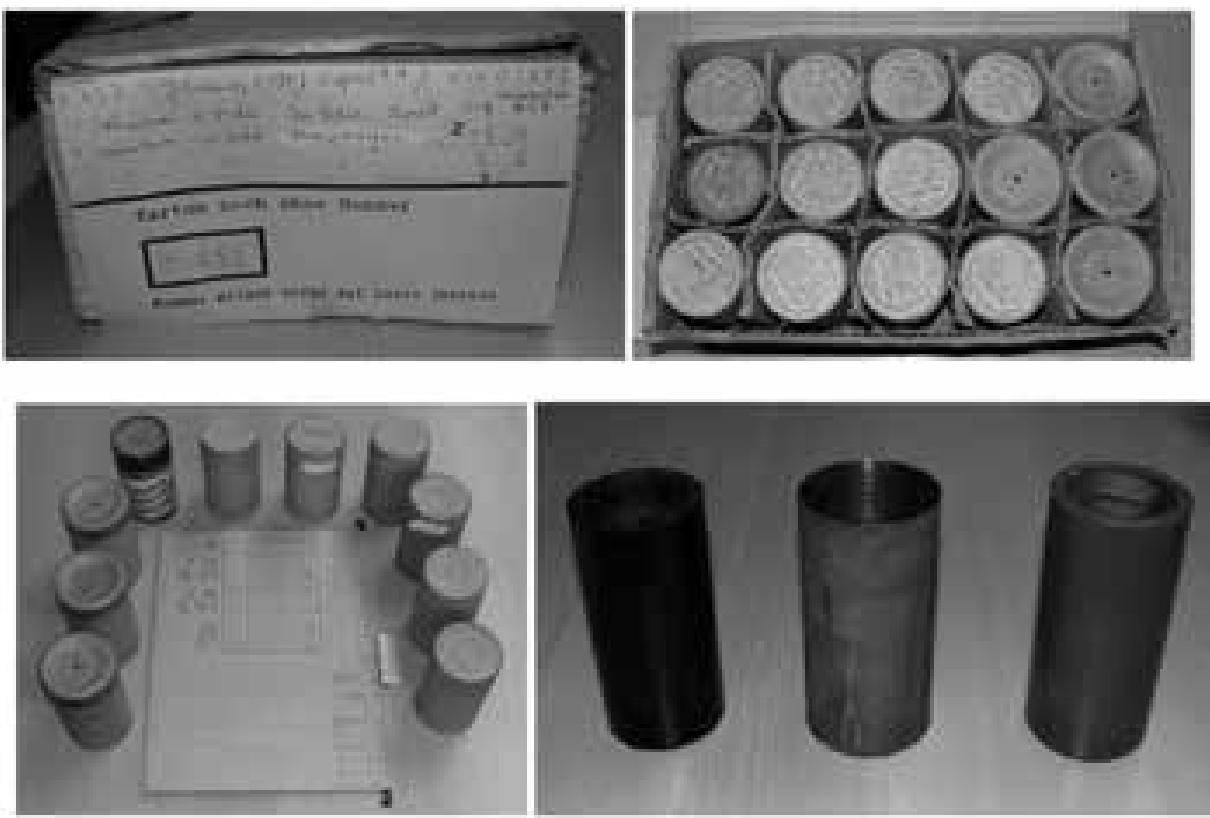

Imagen 1:

Colección "Araukaner", cilindros de cera conservados en el Museo Etnológico de Berlín.

8 pistas que hemos agregado como CD adjunto al libro Historia y conocimiento oral mapuche ${ }^{32}$. Estas grabaciones tienen las siguientes características ${ }^{33}$ :

- Pista 1, cilindro 1 (2' 15"): se inicia con un ngillatun -rogativa- de Regina y continúa con el "canto de machitun", primera versión.

- Pista 2, cilindro 2 (2' 30"): "Canto de machitun", segunda versión.

- Pista 3, copia del cilindro 2 (2' 29"): "Canto de machitun", copia de la segunda versión, aunque tiene cortado el inicio.

- Pista 4, cilindro 3 (51"): canto diferente a los demás, posiblemente de estilo ülo llamekan - canto cotidiano. Los detalles anotados para el título de este cilindro es “... runga ka mapu", cuya traducción es "...Tierra Hundida"34.

- Pista 5, cilindro 4 (3' 2"): canto inicial de Juan Salva y conversación; continúa con otra conversación y un nuevo canto. Este cilindro es muy poco audible. El título otorgado es "Amutuayu" y "Ta papaueñ", cuya traducción es "nos iremos" y "grandes enredaderas".

32 Canio y Pozo 2013.

33 Desde la pista 1 hasta la 4 corresponden a cantos y rogativas de Regina. Desde la pista 5 hasta la 8 son cantos y conversaciones de Juan Salva.

34 Existe la posibilidad de que "runga ka mapu", Tierra Hundida o Tierra Escarbada, sea la toponimia creada para referirse a la ciudad de La Plata, Argentina, ya que corresponde a las características del entorno. Además, Regina expresa en el canto que a ese lugar "fueron trasladas personas mapuches de diversos lugares". 
- Pista 6, cilindro 5 (3' 8"): tiene el mismo título y características del anterior. Posiblemente sea la copia o una segunda versión. Son conversaciones y cantos intercalados.

- Pista 7, cilindro 6 (2' 18"): "Canto de machitun", poco audible en un comienzo, pero al avanzar recupera el sonido. Es continuo y repetitivo.

- Pista 8, cilindro 7 (2’18”): "Diálogo entre dos Kolóng”, es la pista más audible.

En general, siguiendo las advertencias del digitalizador, los cilindros tienen un nivel de deterioro bastante alto. No está claro cuántas veces se habrán escuchado los originales; pero, de acuerdo con los estudios realizados por especialistas del Museo, cada vez que se escucha un cilindro pierde su nitidez, ya que la aguja raspa la cera hasta estropear completamente el cilindro.

\section{ACERCA DE LOS INTÉRPRETES}

Según la ficha de los cilindros 2 y 3 (ver Imagen 2), Regina fue una mujer originaria del pueblo Azul, en la actual Provincia de Buenos Aires, Argentina. El nombre mapuche que se registra de su identidad territorial es "Lelfunche" o Lelfünche, "Gente de las lanicies", anotados históricamente como "Pampas". La fecha en que se registró la grabación es el 9 de agosto de 1905 y se indica que Regina tenía 45 años. Es destacable señalar que la sesión de grabación se realizó en la ciudad de La Plata, ya que allí trasladaron a varias personas que fueron desarraigadas de sus tierras y familias en el marco de la denominada "Campaña del Desierto"35. Lo más posible es que Regina haya vivido junto con su esposo llamado Katrülaf en una casa-habitación donde además compartían el espacio con otros familiares y amigos. Esto se conoce gracias a una fotografía tomada por el mismo Lehmann-Nitsche a la que le anotó "Grupo de Araucanos en La Plata"36.

Por su parte, Juan Salva o "Pichi Nahuel"37 fue un anciano que también trasladaron a la metrópolis de Argentina en tiempos de la ocupación militar. Según la descripción de la ficha de los cilindros 6 y 7 (ver Imagen 3), se reconoce su origen en Villarrica, actual Región de La Araucanía, Chile. Se le asigna como sector territorial el Ngoloche o Nguluche, "Gente de los sectores húmedos-boscosos" (Oeste). La grabación se realizó el 24 de julio de 1907, fecha en que se anota que tiene 70 años de edad. En los diversos manuscritos que se conservan no aparecen mayores detalles sobre cómo dejó su tierra natal y posterior traslado a Buenos Aires o La Plata. Sin embargo, Malvestitti escribe que, luego de vivir en Villarrica, se trasladó a las tierras del longko -cacique- Saihueque cerca del río Limay. Posteriormente se radicó en un sitio llamado Fuerte Roca ${ }^{38}$.

35 En el marco de la Campaña del Desierto se intentó exterminar a los pueblos originarios en beneficio del progreso económico. Muchas personas fueron desarraigadas de sus territorios de origen y trasladadas a Buenos Aires. Desde allí se repartieron al resto del país para que sirviesen en diversos rubros, como porteros, bomberos, policías, barrenderos (Lehmann-Nitsche 1906); mientras que otros hombres, mujeres, niños y niñas fueron entregados al Museo de La Plata para ser estudiados científicamente (Oldani, Suárez y Pepe 2011). Para ahondar sobre las características de este proceso histórico, véase Delrio 2005; Bandieri 2005; Bayer 2006.

36 Fotografía ubicable en el álbum "Araukaner in La Plata”, Instituto Ibero-Americano de Berlín (ficha de búsqueda en el catálogo: N-0070 s 58).

37 Nombre mapuche indicado al reverso de su fotografía, cuyo significado es "Pequeño puma". Está ubicada en una carpeta de cartas conservada en el Instituto Ibero-Americano de Berlín (ficha de búsqueda en el catálogo: N0070 b 1292)

38 Malvestitti 2012: 275. 

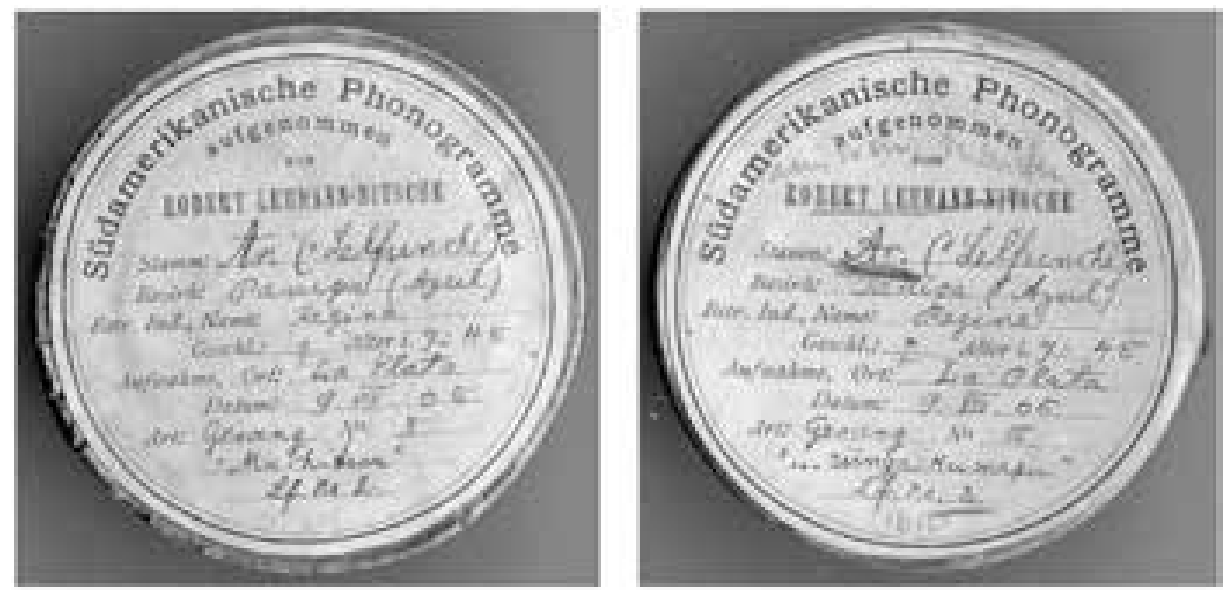

Imagen 2:

Detalle de los cilindros 2 y 3 grabados a Regina el año 1905 y conservados .en el Museo Etnológico de Berlín.
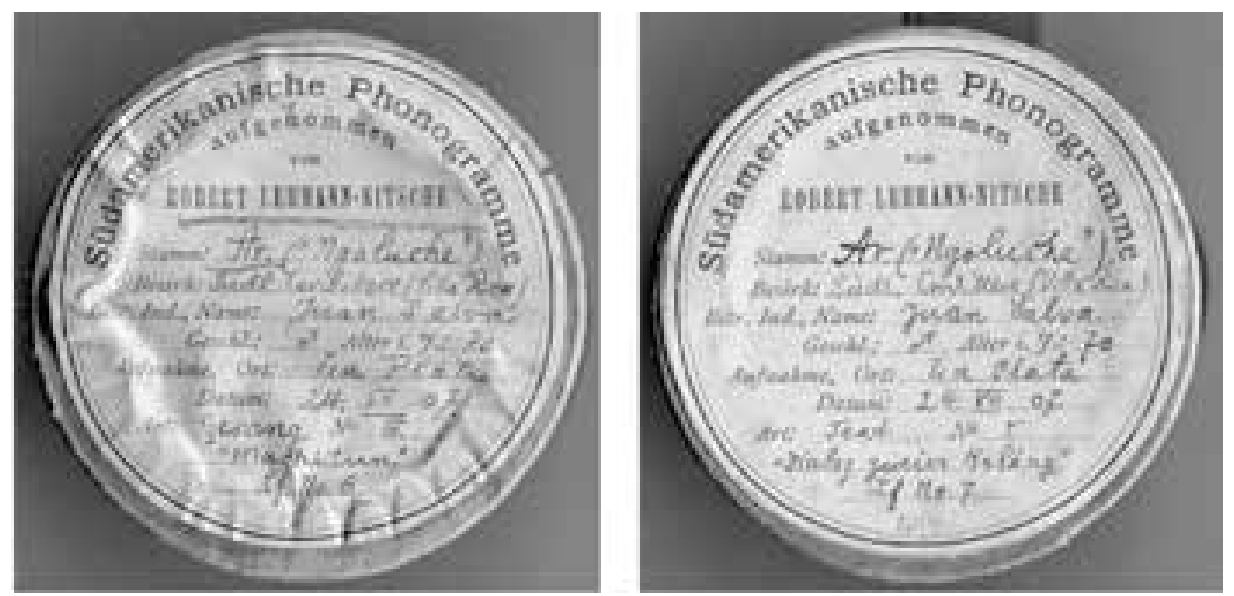

Imagen 3:

Detalle de los cilindros 6 y 7 , grabados a Juan Salva el año 1907 y conservados en el Museo Etnológico de Berlín.

\section{“MACHITUN”, VERSIONES DE REGINA Y JUAN SALVA}

Considerando la importancia histórica que tienen estos cilindros de cera, tomaremos como referencia los cantos "machitun" que ejecutó cada uno de los intérpretes. Posteriormente, haremos una breve comparación entre los contenidos transcritos por nosotros y las anotaciones manuscritas conservadas en el Museo Etnológico de Berlín, ya que aparece una discordancia entre lo escrito y lo que se puede escuchar oralmente. 
Intérprete: Regina

Nombre asignado para el canto: "Machitun"39

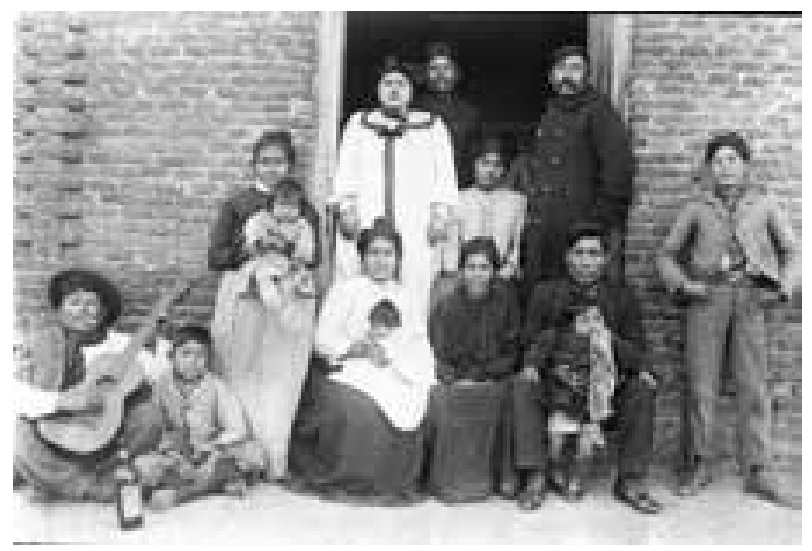

\begin{tabular}{|c|c|}
\hline Transcripción del original ${ }^{40}$ & Traducción al castellano \\
\hline 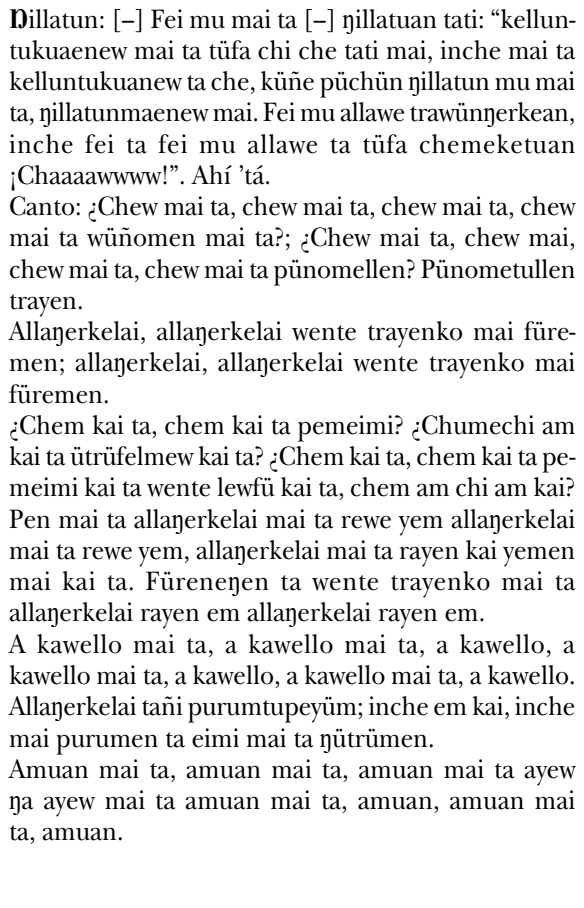 & $\begin{array}{l}\text { Rogativa: [-] Entonces ahora [-] voy a hacer rogativa: } \\
\text { "me tienen que ayudar estas personas, a mí me tienen } \\
\text { que ayudar las personas. Una pequeña rogativa, deben } \\
\text { hacer una rogativa para mí. Por eso, de buena manera } \\
\text { se van a reunir junto a mí, por esa razón es que de } \\
\text { buena manera yo voy a hacer la actividad en este lugar } \\
\text { ¡Chawwww!". Ahí está. } \\
\text { Canto: ¿De dónde, de dónde, de dónde, de dónde } \\
\text { regresé?; ¿A dónde, a dónde, a dónde, a dónde fui } \\
\text { a dejar huellas [a caminar]? Fui a dejar huellas a la } \\
\text { cascada. } \\
\text { Es muy hermosa, es muy hermosa la cima de la cascada } \\
\text { que tuve el gusto [de conocer]; es muy hermosa, es } \\
\text { muy hermosa la cima de la cascada que tuve el gusto } \\
\text { [de conocer]. } \\
\text { ¿Qué cosa, qué cosa observaste? ¿Cómo lo hiciste } \\
\text { cuando aspergeaste [cuando hiciste la rogativa]? ¿Qué } \\
\text { cosa, qué cosa observaste sobre el río, qué será eso? } \\
\text { Observé lo hermoso que es el rewe -altar sagrado } \\
\text { de la machi-, es hermoso el rewe, son hermosas las } \\
\text { flores que fui a buscar. Me han ayudado en la cima } \\
\text { de la cascada, las flores son hermosas, las flores son } \\
\text { hermosas. } \\
\text { A caballo, a caballo sí, a caballo, a caballo sí, a caballo, } \\
\text { a caballo sí, a caballo. Es hermoso el lugar donde se } \\
\text { hace el baile purun; es por eso que yo, yo fui a bailar, } \\
\text { porque tú me has llamado. } \\
\text { [Yyo dije] voy a ir, voy a ir, voy a ir hacia ese lugar, hacia } \\
\text { ese lugar voy a ir, voy a ir, voy a ir, voy a ir. }\end{array}$ \\
\hline
\end{tabular}

39 La pista 1 en el CD que se adjunta al libro de Canio y Pozo 2013 está disponible en www. revistamusicalchilena.uchile.cl

40 Para la transcripción de los fonogramas usamos el alfabeto mapuche unificado propuesto por la Sociedad Chilena de Lingüística 1989, modificando el grafema /ng/ por el /y/. 
Intérprete: Juan Salva (Pichi Nahuel)

Nombre asignado para el canto: "Machitun" 41

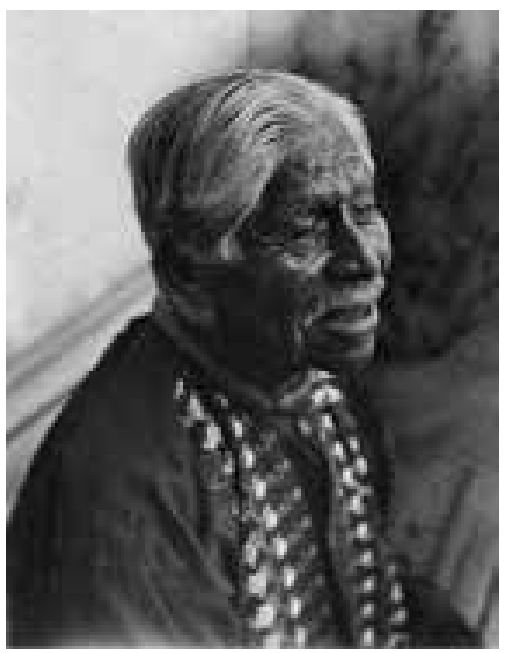

\begin{tabular}{|c|c|}
\hline Transcripción del original & Traducción al castellano \\
\hline 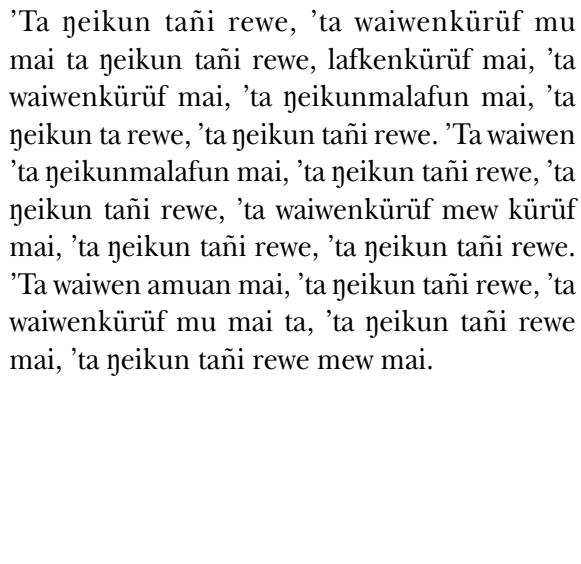 & $\begin{array}{l}\text { Mi rewe se está sacudiendo fuertemente, gracias } \\
\text { al fuerte viento del Sur se está sacudiendo mi } \\
\text { rewe, es el viento del lago/mar, con el fuerte } \\
\text { viento del Sur es que se ha sacudido, fuerte- } \\
\text { mente se ha sacudido el rewe, fuertemente se } \\
\text { ha sacudido mi rewe. Con el fuerte viento del } \\
\text { Sur es que se ha sacudido, fuertemente se ha } \\
\text { sacudido mi rewe, fuertemente se ha sacudido } \\
\text { mi rewe, con el fuerte viento del Sur, con el } \\
\text { viento, fuertemente se ha sacudido mi rewe, } \\
\text { fuertemente se ha sacudido mi rewe. Con el } \\
\text { fuerte viento del Sur me iré, fuertemente se ha } \\
\text { sacudido mi rewe, con el fuerte viento del Sur } \\
\text { es que fuertemente se ha sacudido mi rewe, } \\
\text { fuertemente se ha sacudido mi rewe. }\end{array}$ \\
\hline
\end{tabular}

Desde el punto de vista comparativo, ambos cantos tienen connotaciones sagradas y simulan la ejecución directa que la/el machi hace frente a su rewe y alrededor de las personas presentes. En el caso de Regina se destaca la realización de una rogativa previa, lo que tiene bastante cercanía con los procedimientos que se efectúan en la actualidad, para luego dar paso a su entonación.

${ }^{41}$ La pista 7 en el CD que se adjunta al libro de Canio y Pozo 2013 está disponible en www. revistamusicalchilena.uchile.cl 
Por su parte, Juan Salva expresa el canto con bastante serenidad, ello se debe a su avanzada edad y al estilo de la variante lingüística del sector territorial de origen (Villarrica). La repetición constante de los mismos versos es una característica que se mantiene hoy tanto en los cantos como en las rogativas.

Una problemática necesaria de destacar es la diferencia entre los contenidos transcritos anteriormente y los que propuso el mismo investigador Lehmann-Nitsche, los que se presentan en las imágenes 4 y 5 .
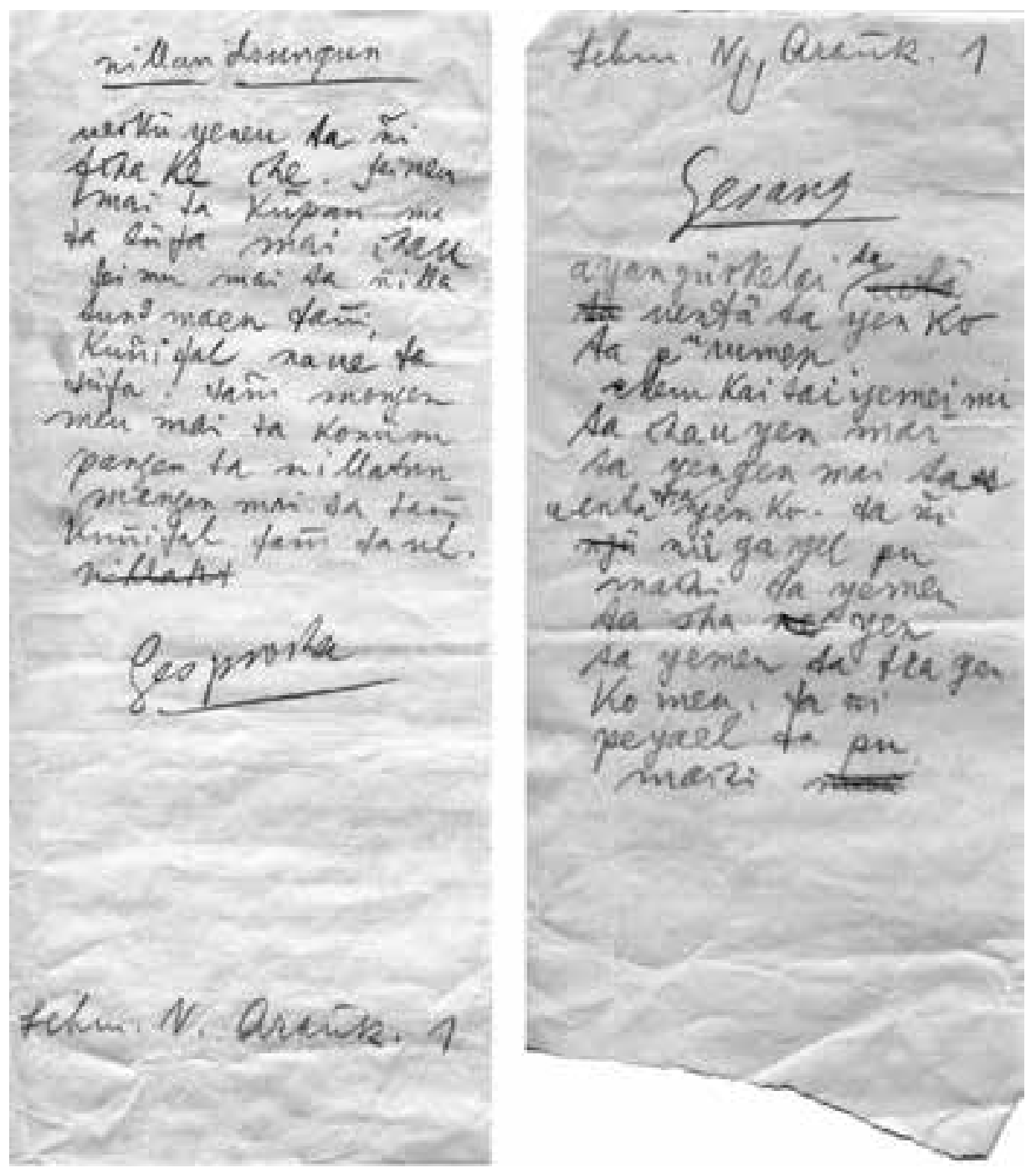

\section{Imagen 4:}

Hoja con la transcripción del "machitun" interpretado por Regina y conservado en el Museo Etnológico de Berlín. 


\begin{tabular}{|c|c|}
\hline Transcripción del original & Propuesta de traducción al castellano \\
\hline $\begin{array}{l}\text { Nillan dsungun } \\
\text { Uerkü yeneu ta ñi fcha ke che. Feimeu mai ta küpan } \\
\text { mai ta tüfa mai chau. Fei mu mai ta ñilla tung maen } \\
\text { tañi kuñifal naué ta tüfa. Tañi mongen meu mai ta } \\
\text { konüm pangen ta nillatun mangen mai ta tañi kuñifal } \\
\text { tañi taué. } \\
\text { Gesproche } \\
\text { Gesang } \\
\text { Ayangürkelai ta uentä ta yen ko ta pu rumen. Chem } \\
\text { kai tai yemeimi ta chauyen mai ta yengen mai ta uentä } \\
\text { tra/yen ko. Ta ñi nü ga ngel pu machi ta yemen ta } \\
\text { sha yen ta yemen ta trayen ko meu. Ta ñi peyael ta } \\
\text { pu machi. }\end{array}$ & $\begin{array}{l}\text { Rogativa } \\
\text { Me ha enviado mi gente anciana, por eso he venido } \\
\text { hasta aquí ¡Chaw! Por eso, esta tu humilde hija, hará } \\
\text { rogativa. Porque he sobrevivido, por eso participo y } \\
\text { me dan fuerza para la rogativa, a esta tu humilde hija. } \\
\qquad \text { Hablado } \\
\text { Canto } \\
\text { Es hermoso en la cima de la cascada donde subí. } \\
\text { ¿Qué he ido a buscar? Fui allí, me llevaron a la cima } \\
\text { de la cascada; fui a buscar flores en la cascada para } \\
\text { que las machi puedan recibirlas, así las machi podrán } \\
\text { apreciarlas. }\end{array}$ \\
\hline
\end{tabular}

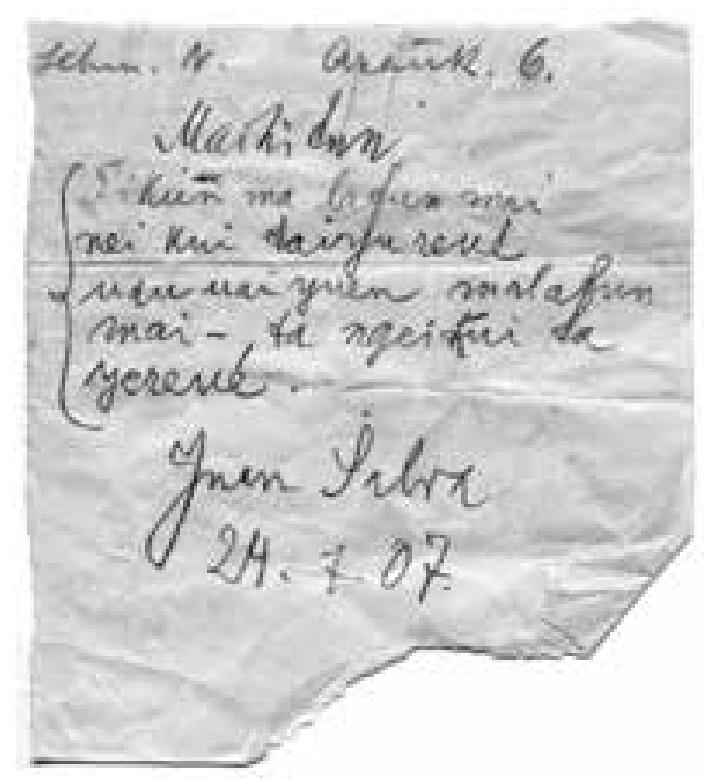

Imagen 5:

Hoja con la transcripción del "machitun" interpretado por Juan Salva y conservado en el Museo Etnológico de Berlín.

\begin{tabular}{|l|l|}
\hline \multicolumn{1}{|c|}{ Transcripción del original } & \multicolumn{1}{c|}{ Propuesta de traducción al castellano } \\
\hline $\begin{array}{l}\text { Machitun } \\
\begin{array}{l}\text { Pikun ma lafun mai nei kui taiyu reué uau uai yuen } \\
\text { malafun mai - ta ngei kui ta yereué. }\end{array}\end{array}$ & $\begin{array}{l}\text { Ritual de machi } \\
\text { Ha venido [el viento] del Norte, [por eso] se ha } \\
\text { movido nuestro rewe; ha venido [el viento] del Sur, } \\
\text { [por eso] se ha movido el rewe. }\end{array}$ \\
\hline
\end{tabular}


Como se podrá apreciar, existe una amplia diferencia entre lo que transcribió el recopilador y lo que se puede escuchar en los originales. Aquí se presenta una disyuntiva metodológica sobre cómo se escribieron los textos. Al referirse Miguel García a la manera en que Lehmann-Nitsche grabó algunos cantos y conversaciones del pueblo chiriguano, comenta que "inmediatamente después de realizar una grabación procuraba transcribir el texto en chiriguano y que, además, intentó sin éxito hallar alguien que pudiese ayudarlo con la traducción al español. No obstante dejó un manuscrito con la transcripción ortográfica en chiriguano de todos los textos de los cantos y con la traducción de tres de ellos al español provista por un misionero no identificado" ${ }^{42}$. En el caso de la grabación a personas tehuelches el procedimiento es diferente. Confeccionó un manuscrito en el que se "incluye las transcripciones de la mayoría de las narraciones en escritura fonológica con traducción al español y al alemán, y una breve introducción donde hace saber que uno de los aborígenes fue quien hizo la traducción de los textos del tehuelche al español, a partir de la cual él realizó la versión en alemán"43. También asegura que "inmediatamente después de cada registro Lehmann-Nitsche pedía a los colaboradores que le dictaran el texto del canto que acababa de ser ejecutado" 44 . Un detalle importante que se debe considerar es que los intérpretes escuchaban inmediatamente su propia grabación. Si bien para el caso mapuche no agrega las impresiones que sintieron, sí lo hizo cuando observó a personas tehuelche:

"Poder escuchar así de inmediato su propia voz les causaba un asombro sin límites y casi consternación; pero al mismo tiempo les entusiasmaba tanto el asunto que cantaban para mí todo lo que quería [...]. Hice que esa gente cantara exactamente igual como acostumbraba, no con una pronunciación más acentuada, lo cual hubiera sido deseable a los efectos de una transcripción más fácil, ni tampoco más fuerte o silencioso. Por eso, en la medida posible con el fonógrafo de aquel tiempo, los fonogramas son fiel reflejo del canto" 45 .

Con estos datos se puede interpretar lo siguiente en cuanto a los fonogramas grabados a Regina y Juan Salva:

1. Las grabaciones se efectuaron en un lugar cerrado, con las mejores condiciones que se ofrecía en la época, ya sea dentro de una habitación o en el mismo Museo de La Plata.

2. Una vez terminado el canto, los interlocutores escucharon inmediatamente lo que habían expresado.

3. Existen dos posibilidades: (1) Lehmann-Nitsche les pidió transcribir 'lo que habían dicho', pero no lo que realmente se escuchó en el cilindro, lo que parece haber desconfigurado la correlación entre lo oral y lo escrito; (2) para estos fonogramas, el recopilador no alcanzó a seguir el procedimiento de escucha junto con sus interlocutores, ante ello propuso una transcripción de acuerdo con sus propios conocimientos. Por esta razón es que el fonograma 3 lo rotula "incomprensible" y el 7 lo deja "sin texto", expresiones que difícilmente hayan sido indicadas por Regina y Juan Salva.

\footnotetext{
42 García 2009: 91.

43 García 2009: 93.

44 García 2009: 94.

45 Lehmann-Nitsche, citado en García 2009: 93-94.
} 
Más allá de esta discusión sobre los procedimientos seguidos por el investigador, lo valorable es que estos cilindros de cera continúan siendo audibles y, gracias a ello, se ha logrado proponer una transcripción y traducción de acuerdo con los textos originales, recuperándose así un patrimonio inestimable de aquellas personas que participaron constantemente en la obra inconclusa de Lehmann-Nitsche.

\section{CANTOS MAPUCHES EN PERSPECTIVA HISTÓRICA}

$\mathrm{Al}$ considerar las referencias que registraron cantos mapuches a principios del siglo veinte, aparecen aquellos que hicieron grabaciones en cilindros de cera u otro formato tecnológico. Pero la evolución más significativa se produce en la década de los setenta, momento en que antropólogos, artistas y sellos discográficos recopilan las tradiciones, cantos, conversaciones y música de las sociedades originarias de América y del mundo, procedimientos que se han proyectado hasta nuestros días.

Para los cantos rituales tayül se han hecho descripciones bastante extensas ${ }^{46}$. Sin embargo, los de estilo pillañtun o pillantun solo presentan definiciones en diccionarios ${ }^{47}$ o breves acotaciones sobre sus características ${ }^{48}$. Algunos aportes orales de importancia son compilaciones grabadas a las mismas personas que primeramente ejecutan dichos cantos. Ejemplo de esto son los tayül de Julia Nahuelquir, Lorenza Queupan, Rosa Prafil y Lucerinta Cañumil, publicados por Lucía Golluscio en el Archivo de las Lenguas Indígenas de Latinoamérica ${ }^{49}$; y los pillañtun de las mach $i$ Juana Reimán ${ }^{50}$ e Hilda Meliqueo ${ }^{51}$, disponibles en casetes y discos compactos. Con estos antecedentes se perfilan algunos elementos de continuidades y cambios, diferenciándose así tres ámbitos: (1) los tipos de canto (tayül o pillañtun); (2) el uso de instrumentos; y (3) los contenidos. Si bien los dos primeros presentan variaciones y requieren de investigaciones en sectores territoriales específicos; es en los "contenidos" donde se observa una mayor correspondencia. En el "canto de machi" aportado por Domingo Segundo Wenuñamko aparece Ngünechen como ser superior a quien se le solicitan las hierbas medicinales, mediante la expresión "mariepu rajiñwenu llaweñ" (las doce hierbas medicinales que están en medio del cielo). Asimismo, la machi de Chapod, cuyo canto recopiló Isamitt, plantea una relación con Ngünechen en cuanto le entregó el don que bajó desde el cielo, lugar donde existen cuatro flores concedidas por Chaw y $\tilde{N} u k e$. Esto último tiene bastante relación con el canto de Regina, en el que relata el viaje hacia el mundo celeste, visualizando allá una cascada desde donde extrajo flores que le servirán como medicina.

$\mathrm{Al}$ escuchar grabaciones contemporáneas aparecen estos hitos de manera reiterada, aunque con algunos cambios en la nomenclatura utilizada. Por ejemplo, la machi Hilda Meliqueo expresa en su pillañtun un acercamiento hacia los seres espirituales empleando las siguientes concepciones: Chaw Ngünechen, Chaw Dios, Wenumapu Chaw-Padre del Cielo-, Wenumapu Nuke-Madre del Cielo-, entre otros, para luego solicitarles a ellos y ellas las medicinas que deben descender a la tierra y que le permitan tratar a la persona enferma. En

46 Véase Pelinski y Casamiquela 1966; Robertson 1976; Grebe Vicuña 1989.

47 Erize 1960.

48 Grebe 1973; Bacigalupo 2001.

49 Grabaciones disponibles en la página web de este archivo perteneciente a la Universidad de Texas en Austin: http://www.ailla.utexas.org/site/welcome_sp.html (consultada el 19/03/2013).

50 Pista 6 del disco Mapuche producido por Ernesto González y publicado por el Sello Alerce (1984).

51 Pista 1 del disco Mapuches/Chili producido por Buda Musique y publicado por el Sello Universal (1997). 
ese sentido, la vinculación con contenidos ya trabajados en las otras grabaciones es bastante amplia, pero esta vez existe la seguridad de que el canto proviene de una especialista. Ante esto caben varias preguntas: ¿Cómo habrá sido un canto entonado por la misma machi en el tiempo que se registraron las grabaciones de Lehmann-Nitsche y Augusta? ¿Cuáles son los cambios de estilo que incorporaron Regina, Juan Salva y Domingo Segundo Wenuñamko en las versiones que originalmente escucharon? ¿En qué contexto aprendieron aquellos cantos los intérpretes? Lamentablemente los recopiladores no anotaron mayores datos etnográficos, lo que impide apreciar detalles. No obstante, con los actuales medios tecnológicos se supera esta problemática, gracias a que los trabajos de audio registran estos cantos en su propio entorno o por lo menos en un ambiente cercano.

\section{CONSIDERACIONES FINALES}

Los cilindros de cera, discos de goma (vinilos), cintas magnetofónicas y las actuales grabaciones que producen inmediatamente un archivo digital, constituyen la base histórica que han tenido los archivos sonoros. Pero los que corren más peligro de perder su información, definitivamente, son los cilindros de cera. En ese sentido, el trabajo de conservación y restauración que se desarrolla en el Museo Etnológico de Berlín es totalmente valorable. Gracias a este trabajo podemos escuchar unas grabaciones realizadas a personas mapuches hace más de cien años, todas ellas se consideran un patrimonio histórico de gran importancia.

Uno de los desafíos que surgen para futuras investigaciones es la descripción densa y en terreno del estilo pillañtun, así como también buscar nuevas pistas que permitan organizar sincrónicamente los diversos tayül que se entonan en el contexto ceremonial. Es de esperar que los estudios antropológicos y musicológicos avancen en esta dirección, de tal manera que se logre comprender el canto situado en su complejo contexto sociocultural.

\section{BIBLIOGRAFÍA}

\section{Libros, artículos y capitulos de libros}

Allende, Pedro Humberto

1945 "Música araucana", Antártica, N XII (agosto), pp. 84-88.

Augusta, Félix

1911 "Zehn Araukanerlieder", Anthropos, VI/5, pp. 84-88.

Bacigalupo, Ana

2001 La voz del kultrun en la modernidad: tradición y cambio en la terapéutica de siete machi mapuche. Santiago de Chile: Universidad Católica de Chile.

BANDIERI, SUSANA

2005 Historia de la Patagonia. Buenos Aires: Sudamericana.

Bayer, Osvaldo

2006 Historia de la crueldad argentina. Tomo I. Julio Argentino Roca. Buenos Aires: Centro Cultural de la Cooperación Floreal Gorini.

Bilbao, Santiago

2004 Rememorando a Roberto Lehmann-Nitsche. Buenos Aires: La Colmena. 
Canio, Margarita

2011 Kuifikecheyem montulu malon mu, sobrevivientes del "malon" y sus relatos históricos. Textos en lengua mapuche recopilados por Robert Lehmann-Nitsche (1901-1926). Trabajo final del programa Master en Estudios Americanos. Sevilla: Universidad de Sevilla.

Canio, Margarita y Gabriel Pozo

2013 Historia y conocimiento oral mapuche. Sobrevivientes de la "Campaña del Desierto" y "Ocupación de la Araucanía" (1898-1926). Santiago de Chile: Imprenta LOM.

Chicote, Gloria y Miguel García

2009 "La cultura de los márgenes devenida en objeto de la ciencia. Robert LehmannNitsche en la Argentina”, Iberoamericana, IX/33 (enero-marzo), pp. 103-119.

Delrío, Walter

2005 Memorias de expropiación. Sometimiento e incorporación indígena en la Patagonia (18721943). Buenos Aires: Universidad Nacional de Quilmes.

ERIZE, ESTEBAN

1960 Diccionario comentado mapuche-español. Buenos Aires: Cuadernos del Sur.

FARro, Máximo

2009 La formación del Museo de La Plata: coleccionistas, comerciantes, estudiosos y naturalistas viajeros a fines del siglo XIX. Rosario: Prohistoria.

Garrido Escobar, Francisco J. y Renato D. Menare Rowe

2014 "Efraín Band y los inicios de la fonografía en Chile", RMCh, LXVIII/221 (enerojunio), pp. 52-78. Disponible en www.revistamusicalchilena.uchile.cl

García, Miguel

2009 "Grabaciones en cilindros de Argentina. Robert Lehmann-Nitsche 1905-1909. Música criolla y aborigen”, en Lars-Christian Koch y Susanne Ziegler (editores). Robert Lehmann-Nitsche. Walzenaufnahmen aus Argentinien 1905-1909. Berlín: Staatliche Museen zu Berlin - Preußischer Kulturbesitz, pp. 76-108.

2011 “Archivos sonoros o la poética de un saber inacabado”, Artefilosofía, № 11 (diciembre), pp. 36-50.

Grebe Vicuña, María Ester

1973 "El kultrún mapuche: un microcosmos simbólico", RMCh, XXVII/123-124 (juliodiciembre), pp. 3-42. Disponible en www.revistamusicalchilena.uchile.cl

1974 "La música alacalufe: aculturación y cambio estilístico", RMCh, XXVIII/126-127 (abril-septiembre), pp. 80-111. Disponible en www.revistamusicalchilena.uchile.cl

1989 "El Tayil mapuche, como categoría conceptual y medio de comunicación trascendente”, Inter-American Music Review, X/2 (primavera-verano), pp. 69-75.

ISAMITT, CARLOS

1934 "El machitun y sus elementos musicales de carácter mágico", Revista de Arte, I/3 (octubre-noviembre), pp. 5-9.

1935 “Cantos mágicos de los araucanos”, Revista de Arte, I/6, pp. 9-13.

1957 "El folklore en la creación artística de los compositores chilenos", RMCh, XI/55 (octubre-noviembre), pp. 24-36. Disponible en www.revistamusicalchilena.uchile.cl

KITTLER, FriEDRICH

1999 Gramophone, Film, Typewriter. California: Standford University Press. 
Koch, Lars-Christian, Susanne Ziegler y Bárbara Göbel

2009 "Prefacio", Robert Lehmann-Nitsche. Walzenaufnahmen aus Argentinien 1905-1909. Berlin: Staatliche Museen zu Berlin - Preußischer Kulturbesitz, pp. 69-70.

LaVín, Carlos

1967 [1925] “La música de los araucanos”, RMCh, XXI/99 (enero-marzo), pp. 57-60.

LEHMANN-Nitsche, RoBERT

1906 "Märchen der argentinischen Indianer", Zeitschrift des Vereins für Volkskunde in Berlin, $\mathrm{N}^{\circ}$ 2, pp. 157-164.

Malvestitti, Marisa

2007 "Waizüfche ñi ngütram: narrativas acerca de la historia indígena en la Norpatagonia de la época del awkan", Anuario, № 8, pp. 225-238.

2008 "Un legado olvidado. Los “Textos Araucanos" de Roberto Lehmann-Nitsche", Museo, III/22 (noviembre), pp. 55-60.

2012 Mongeleluchi zungu. Los textos araucanos documentados por Robert Lehmann-Nitsche. Berlin: Gebr. Mann Verlag.

Oldani, Karina, Miguel Suárez y Fernando Pepe

2011 "Las muertes invisibilizadas del Museo de La Plata", Corpus. Archivos virtuales de la alteridad americana, I/1 (primer semestre), pp. 1-4.

Pelinski, Ramón y Rodolfo Casamiquela

1966 "Músicas de canciones totémicas y populares y de danzas araucanas", Revista del Museo de La Plata, VI/31, pp. 43-80.

Robertson, CAROL

1976 "Tayil as Category and Communication among the Argentine Mapuche: A Methodological Suggestion", Yearbook of the International Folk Music Council, Vol. 8, pp. 35-52.

Salas Viu, Vicente

1967 “Carlos Lavín y la musicología en Chile”, RMCh, XXI/99 (enero-marzo), pp. 8-14. Disponible en www.revistamusicalchilena.uchile.cl

SOCiedad Chilena de Lingüí́stica

1989 Uso del alfabeto mapuche unificado. Temuco: Universidad de La Frontera.

URRUTIA BLONDEL, JoRge

1967 “Carlos Lavín, compositor”, RMCh, XXI/99 (enero-marzo), pp. 61-84. Disponible en www.revistamusicalchilena.uchile.cl

Wiedmann, Albrecht

2009 "Sobre la transferencia y el tratamiento de los cilindros", en Lars-Christian Koch y Susanne Ziegler (editores). Robert Lehmann-Nitsche. Walzenaufnahmenaus Argentinien 1905-1909. Berlin: Staatliche Museen zu Berlin - Preußischer Kulturbesitz, p. 75.

ZIEGLER, SUSANNE

2006 Die Wachszylinder des Berliner Phonogramm-Archivs. Berlin: Ethnologisches Museum, Staatliche Museen zu Berlin.

2009 "Sobre las colecciones de cilindros y su reedición”, en Lars-Christian Koch y Susanne Ziegler (editores). Robert Lehmann-Nitsche. Walzenaufnahmen aus Argentinien 
1905-1909. Berlin: Staatliche Museen zu Berlin - Preußischer Kulturbesitz, pp. 72-74.

2. Otras fuentes de información

Archivos fonográficos, Museo Etnológico de Berlín

"Fonogramas Araucanos" grabados por Robert Lehmann-Nitsche. Archivo Fonográfico de Berlín: siete cilindros de cera más tres copias y sus respectivas fichas de descripción.

Archivos de Robert Lehmann-Nitsche, Instituto Ibero-Americano de BerLín

a) Legajos de manuscritos

N-0070 w 24: Textos Araucanos II.

b) Álbum de fotografías

N-0070 s 58: Araukaner in La Plata.

c) Carpeta de cartas, recortes y fotografías.

N-0070 b 1292: Briefe von Juan Castro u.a. an Robert Lehmann-Nitsche.

\section{DiARIOS NAGIONALES}

La Tercera, sábado 18 de septiembre de 2010, página 36. "La banda sonora del Centenario", por Roberto Farías. Disponible en http://diario.latercera. com/2010/09/18/01/contenido/santiago/32-38993-9-la-banda-sonora-del-centenario.shtml

\section{Discos COMPACTOS}

Mapuche, serie "El Canto del Hombre", grabaciones y master por Ernesto González, Estudios Filmocentro, Santiago de Chile, publicado por el Sello Alerce en febrero de 1984. Número de serie: CDAE 0334.

Mapuches/Chili, diseñado y realizado por Jacques Erwan, producido por Buda Musique, publicado por el Sello Universal, septiembre-octubre de 1997, Estudio La Voix de Son, Bruselas, Bélgica. Número de serie: 3017295.

\section{PÁginas WEB}

Archivo de las Lenguas Indígenas de Latinoamérica, Universidad de Texas en Austin: http://www.ailla.utexas.org/site/welcome_sp.html 